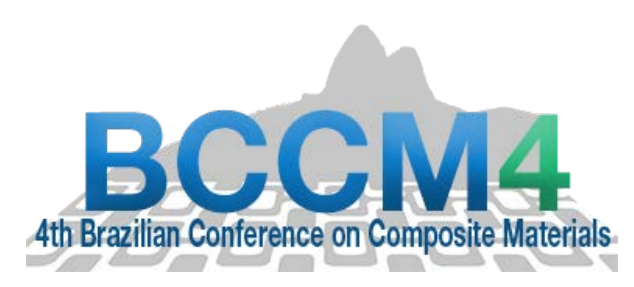

\title{
EFFECTS OF SILICA MICROPARTICLES IN GLASS FIBRE/EPOXY LAMINATES
}

\author{
Aluizio Heleno Ribeiro Junior ${ }^{(1)}$, Juan Eduardo Gomez ${ }^{(2)}$, Devin Wayne Hale ${ }^{(2)}$, Maikson \\ Luiz Passaia Tonatto ${ }^{(1)}$ and Tulio Hallak Panzera ${ }^{(1)}$
}

(1) Centre for Innovation and Technology in Composite Materials, Department of Mechanical Engineering, Federal University of São João del Rei-UFSJ, Brazil

(2) Whitacre College of Engineering, Texas Tech University, United States

https://doi.org/10.21452/bccm4.2018.13.06

\begin{abstract}
Composites have been widely used in engineering applications due to high strength to weight ratios. A large amount of materials used in aeronautics is based on composite materials. This provides motivation to improve the mechanical properties of the existing composite materials. When a glass fibre laminate is subjected to bending stresses, maximum compressive and tensile stresses are generated at its sides of the surface beam. Rigid particles have been added into laminate composites specially to enhance their bending performance attributed to the matrix stiffness and interlaminar shear resistance increases. In order to better assess the enhancement mechanism provided by particle inclusions, this work investigates the incorporation of micro-sized silica on the top, bottom and both surfaces of glass fibre laminates, mitigating the interference of the interlocking effect. Three-point bending and impact test were performed to evaluate hybrid glass fibre composites containing 5, 7.5 and $10 \%$ by weight silica. Although the silica particles lead to increased compressive modulus of epoxy polymers, their positive effect on glass fibre composite under flexural loads was more evident on the bottom beam side subjected to maximum tensile stress. The incorporation of $7.5 \mathrm{wt} \%$ silica microparticles on the bottom surface of the laminates achieved higher flexural behaviour and lower impact resistance.
\end{abstract}

\section{INTRODUCTION}

Composites have been used in a variety of applications in many sectors, especially in the aeronautical industry, due to the need to have strong mechanical properties in a lightweight material [1]. It is common knowledge that the aeronautic industry uses glass fibre composites on aircraft, and therefore this study focuses on glass fibre composites and the incorporation of silica particles on the surface of the laminate composites. The primary cause of delamination in composites that are in-service now is impact damage, involving reductions of residual strength by 
up to $60 \%$. In fact, low impact tolerance is what limits the use of composite laminates. Improvements have been made with the inclusion of micro/nano-particles into Glass Fibre Reinforced Composites (GFRCs) [2].

Some important reasons why glass fibre composites are being used in many fields today are because of their favourable mechanical properties and the low relative cost if used in mass production. Glass fibre composites also have unfavourable mechanical properties that can affect the integrity of the entire component. A simple way to improve the properties of glass fibres is adding multiple types of reinforcements such as particles. Any composite containing more than one type of reinforcement is called 'Hybrid Composite'. A hybrid composite has equally important mechanical properties such as flexural strength and impact toughness [3]. When epoxy polymers are used as adhesives, they tend to add useful mechanical properties, including high modulus, failure strength, and good performance at high temperatures. However, this accompanies a negative side effect, which causes the material to become relatively brittle [4]. These properties lead engineers to try to remove or strengthen these negative properties by adding rigid particles within the matrix phase and creating a stronger bond between the matrix and fibre phases; which allows a stiffer and durable material for specific applications.

Failure due to the impact loading creates the motivation to strengthen composite materials. The inclusion of silica microparticles in HGFRCs creates a Hybrid Glass Fiber Reinforced Composite (HGFRCs); which is generally done to enhance the impact strength without losing the flexural strength. There is evidence that the inclusion of silica microparticles to the compressive side of the laminate GFRC has shown a significant increase in specific flexural strength. The mean impact strength was increased by $9.8 \%$ with the inclusion of 5wt\% of silica particles in GFRCs [5]. Experimental and computational efforts have been addressed to try to understand the strengthen mechanism involved [6]. However, in most of the models and tests, the laminates have been reinforced between each layer. In the present work, the particles were added only on the upper and lower surfaces of the laminates, where the compressive and tensile stresses are maximal under three-point bending test. The motivation of using micro rather than nanoparticles is the ability to easily spread the microparticles along large surface areas with a constant concentration. The process that nanoparticles must undergo is much more complex and the time that prevents the constant concentration within GFRCs takes days, whereas the process of the microparticles can be completed in minutes [7].

This study investigates the influence of silica microparticles (0, 5, 7.5, and 10wt\%) and the silica inclusion site (top, bottom and whole sample) on the flexural modulus, flexural strength and impact resistance of hybrid with glass fibre reinforced composites. To better assess the findings for the hybrid composites, the epoxy polymers reinforced with particles at 5, 7.5 and 10wt\% were evaluated under tensile and compressive tests.

\section{MATERIALS AND METHODS}

\subsection{Materials and sample preparation}

Renlam M epoxy resin and Ren HY 956 hardener used at 5:1 ratio was supplied by Huntsman (Brazil). The glass fibre material was provided by Resinplast (Brazil). The silica microparticles were obtained from Moinhos Gerais Company (Brazil). A particle size range of 325-400 (44$37 \mu \mathrm{m}$ ) were considered. Ten cross-ply fabrics of glass were laminated considering a $70 \%$ matrix volume fraction to reach $2 \mathrm{~mm}$ thickness recommended by the ATSM D790 [8] and ATSM D6110 [9] standards for flexural and impact tests, respectively. 
The silica particles were hand mixed with the epoxy resin for 5 minutes, then the hardener was combined and mixed for another 5 minutes. Three different levels of particle amount were considered: $5 \mathrm{wt} \%, 7.5 \mathrm{wt} \%$, or $10 \mathrm{wt} \%$. The particulate reinforced matrix phase was placed at three different sites: the top surface, the bottom surface and thorough the sample, leading to 9 experimental conditions and a non-particulate reference (see Table 1). A constant pressure of $10 \mathrm{kPa}$ was applied to the laminate for 24 hours, then left for another 7 days to cure at room temperature $\left(\approx 21 \pm 1^{\circ} \mathrm{C}\right)$. Two replicates were considered in the experiment. Five samples for each test and condition were fabricated, running the total of 200 specimens.

Table 1: Full factorial design $\left(3^{2}\right)$.

\begin{tabular}{ccc}
\hline Condition & $\begin{array}{c}\text { Particle } \\
\text { site }\end{array}$ & $\begin{array}{c}\text { Silica inclusion } \\
\text { (wt.\%) }\end{array}$ \\
\hline 1 & Top & 5 \\
\hline 2 & Top & 7.5 \\
\hline 3 & Top & 10 \\
\hline 4 & Bottom & 5 \\
\hline 5 & Bottom & 7.5 \\
\hline 6 & Bottom & 10 \\
\hline 7 & Both & 5 \\
\hline 8 & Both & 7.5 \\
\hline 9 & Both & 10 \\
\hline 10 & Reference & 0 \\
\hline
\end{tabular}

Tensile and compressive samples were manufactured based on epoxy polymer and silica particles only. The particles were hand-mixed with epoxy polymer for 5 minutes and then poured into silicone moulds fabricated according to the ASTM standards [10, 11].

\subsection{Mechanical tests}

The samples with $50 \times 12.7 \times 2 \mathrm{~mm}$ were tested at $2 \mathrm{~mm} / \mathrm{min}$ under three-point bending using a Shimadzu AG-X plus test machine equipped with $100 \mathrm{kN}$ load cell. The flexural strength and modulus were calculated based on ATSM D790 [8]. Charpy impact testing was carried out using XJJ-50 pendulum machine. The samples with $80 \times 10 \mathrm{~mm}$ were tested according to ASTM D6110 standard [9]. The impact resistance was calculated. Minitab 18 software were used to perform the Design of Experiment (DoE) and Analysis of Variance (ANOVA) [12, 13].

In order to better evaluate the findings for the hybrid composites, the epoxy polymers reinforced with particles at 5, 7.5 and 10wt\% were characterize under tensile [10] and compressive tests [11].

\section{RESULTS}

\subsection{Effect of silica on matrix phase}

Table 2 shows the mechanical properties of the epoxy polymer with silica microparticles. Although a reduction in tensile stiffness at levels of 5 and $7.5 \mathrm{wt} \%$ by silica was evidenced, a slight 
increase was found in $10 \mathrm{wt} \%$. In contrast, the compressive modulus increased as much as the amount of silica particles. Tensile strength data were slightly reduced, while the mean values of the compressive strength were enhanced by the incorporation of silica. Ferreira [14] studied the incorporation of micro-sized silica into epoxy polymer at 2.5, 5, 7.5 and 10wt\%. The compressive modulus and strength values presented in this work were $11.3 \%$ and $3.7 \%$ higher than those obtained by Ferreira [14]. The strength of micro-particulate composites relies on the effectiveness of stress transfer between resin and fillers, which are associated due to the interplay between of three factors: particle size, particle/matrix interfacial adhesion and particle loading, which cannot always be separated [15].

Table 2: Mechanical properties for particulate reinforced epoxy polymer

\begin{tabular}{ccccc}
\hline $\begin{array}{c}\text { Silica inclusion } \\
\text { (wt. \%) }\end{array}$ & $\begin{array}{c}\text { Tensile } \\
\text { Modulus (GPa) }\end{array}$ & $\begin{array}{c}\text { Tensile strength } \\
(\mathrm{MPa})\end{array}$ & $\begin{array}{c}\text { Compressive } \\
\text { modulus (GPa) }\end{array}$ & $\begin{array}{c}\text { Compressive } \\
\text { strength (MPa) }\end{array}$ \\
\hline $0 \%$ & $2.10 \pm 0.13$ & $39.50 \pm 0.97$ & $2.20 \pm 0.09$ & $68.70 \pm 4.34$ \\
$5 \%$ & $2.02 \pm 0.21$ & $39.21 \pm 0.51$ & $2.35 \pm 0.08$ & $71.15 \pm 1.34$ \\
$7.5 \%$ & $1.98 \pm 0.22$ & $38.98 \pm 1.77$ & $2.43 \pm 0.10$ & $71.57 \pm 2.18$ \\
$10 \%$ & $2.20 \pm 0.14$ & $37.88 \pm 1.67$ & $2.53 \pm 0.06$ & $73.60 \pm 0.53$ \\
\hline
\end{tabular}

\subsection{Flexural and Impact behaviour of HGFRCs}

Table 3 shows the results of the analysis of variance (ANOVA) for the mean flexural and impact data. P-value values less than 0.05 (5\%) are considered significant at a 95\% confidence level. Drumond et al. [16] emphasized that the effects of interaction between factors are more important than individual factors, because they had better explain the behaviour of responses when considered significant. The effects of second-order interaction were significant for all responses, as shown by the P-values underlined in Table $3 . \mathrm{R}^{2}$ values close to $100 \%$ indicate well-fitted data to the statistical model.

Figure 1 shows the interaction effect plots for the mean flexural strength (a) and modulus (b). Higher flexural strength values were achieved when silica particles were incorporated, especially on the bottom beam side, followed by the top sample surface (Figure 1a). The inclusion of particles on the top surface did not provide greater flexural strength as expected. It is noteworthy that the inclusion of particles on both sides led to reduced strength compared to the reference condition. The silica amount levels did not substantially change the strength of the composites. In contrast, 7.5wt\% silica achieved higher stiffness values for all added sites (Figure 1b). The highest flexural modulus was reached when $7.5 \mathrm{wt} \%$ of silica was added to the bottom surface of the laminate. Hybrid composites only achieved a modulus larger than the reference condition when fabricated with $7.5 \mathrm{wt} \%$ of silica on the bottom or top sides of the beam.

The bending test combines tensile (bottom beam side), compressive (upper beam side) and shear loadings [1]. Considering the particles were added on the laminate surfaces, there is no interlocking effect in the interlaminar region to be considered. Based on the findings presented in Table 2 for the reinforced matrix phase, it was expected to have greater flexural behaviour for samples reinforced especially on the upper surface under compressive loads. The incorporation of particles on only one side of the laminate can affect the normal load distribution generated by the bending. The presence of silica on the bottom surface may also contribute to retard crack 
propagation, as reported in the open literature $[2,4,6]$, which may be responsible for increasing the flexural performance of hybrid composites.

Table 3: ANOVA

\begin{tabular}{cccc}
\hline \multirow{2}{*}{ Experimental factor } & \multicolumn{3}{c}{ P-value $\leq 0.05$} \\
\cline { 2 - 4 } & Flexural Strength & Flexural Modulus & Impact Strength \\
\hline Percent & 0.045 & 0,000 & 0.000 \\
\hline Position & 0.000 & 0,000 & 0.000 \\
\hline Percent*Position & $\mathbf{0 . 0 3 0}$ & $\mathbf{0 , 0 0 3}$ & $\mathbf{0 . 0 1 4}$ \\
\hline $\mathrm{R}^{2}$-adjusted (\%) & $\underline{98.86 \%}$ & $\underline{96.96 \%}$ & $\underline{98.97 \%}$ \\
\hline
\end{tabular}
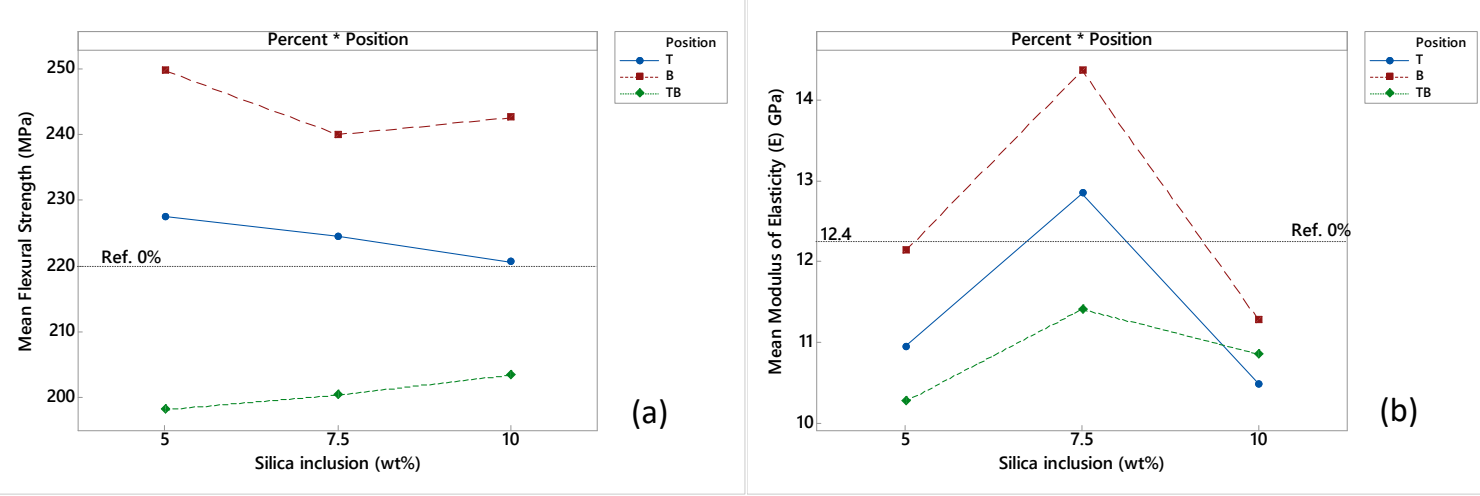

Figure 1: Interaction effect plots (a) for mean flexural strength and (b) mean flexural modulus

Figure 2 shows the interaction effect plot for the mean impact resistance. Since the inclusion of silica increased the stiffness of the composites, an opposite behaviour for the impact resistance was expected, as shown in Figure 2. It should be noted that the reference condition (without particles) achieved the highest impact resistance at $135 \mathrm{~kJ} / \mathrm{m}^{2}$. Cao and Cameron [6] have attributed positive effects on impact response by adding micro particles in the interlaminar region of glass fibre composites due to the presence of fibre pull-out mechanism and increased interlocking effect. However, such a mechanism cannot be considered in the present work since the particles were added on the surfaces of the laminate and not in the interlaminar regions.

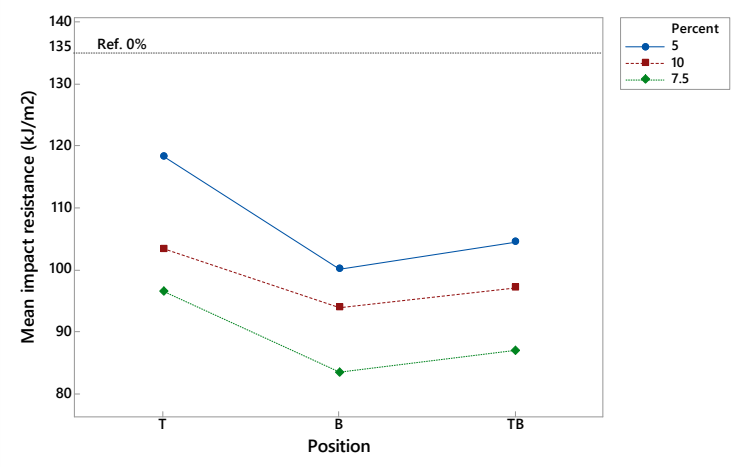

Figure 2: Interaction effect plot for mean impact resistance. 
$4^{\text {th }}$ Brazilian Conference on Composite Materials. Rio de Janeiro, July $22^{\text {nd }}-25^{\text {th }}, 2018$

\section{CONCLUSION}

The main conclusions are following described:

- The inclusion of silica particles in the epoxy polymer led to increased compressive modulus (2.53GPa) and strength (73.60MPa). However, no substantial change was verified for the tensile behaviour.

- The inclusion of particles on both sides of glass fibre composites led to reduced flexural strength and stiffness compared to the reference condition.

- Hybrid glass fibre composites only achieved a modulus larger than the reference condition (without particles) when fabricated with $7.5 \mathrm{wt} \%$ of silica on the bottom or top sides of the laminate.

- The incorporation of $7.5 \mathrm{wt} \%$ silica microparticles on the bottom surface of the laminates achieved higher flexural behaviour and lower impact resistance.

- The highest impact resistance $\left(135 \mathrm{~kJ} / \mathrm{m}^{2}\right)$ was achieved by the reference condition without particles, followed by hybrid laminates made with $5 \mathrm{wt} \%$ of particles added in the top surface.

\section{ACKNOWLEDGEMENTS}

The authors would like to thank Texas Tech University, CNPq (PP-306767/2016-3) and FAPEMIG (PPM-00075-17) for the financial support provided.

\section{REFERENCES}

[1] Santos, J. C. and Panzera, T. H., 'Hybrid silica micro and PDDA/nanoparticles-reinforced carbon fibre composites’, (Journal of Composite Materials, vol. 51, Published June 17, 2016) 783-795.

[2] Torres, R. B. and Santos, J.C., 'Hybrid glass fibre reinforced composites containing silica and cement microparticles based on a design of experiment', (Polymer Testing, vol. 57, 2017) 87-93.

[3] Hasan, I., Qingtao, W., Ahmed, A., and Wei, L., 'Effect of Hybrid Ratio and Laminate Geometry on Compressive Properties of Carbon/Glass Hybrid Composites', (Fibers and Polymers 2016, Vol.17, No.1), 117-129.

[4] Kinloch, A. J., Masania, K., Taylor, A. C., Sprenger, S., 'The fracture of glass-fibre-reinforced epoxy composites using nanoparticle-modified matrices', (Journal of Materials Science, vol. 43, Published February, 2008) 1151-1154

[5] Silva, L. J., Panzera, T. H., Christoforo, A. L., 'Micromechanical Analysis of Hybrid Composites Reinforced with Unidirectional Natural Fibres, Silica Microparticles and Maleic Anhydride', (Materials Research, vol.15 no.6 São Carlos December, 2012).

[6] Cao, Y. and Cameron, J., 'Impact Properties of Silica Particle Modified Glass Fiber Reinforced Epoxy Composite', (Journal of Reinforced Plastics and Composites, May 1, 2006).

[7] Cao, Y. and Cameron, J., 'The Effect of Curing Conditions on the Properties of Silica Modified Glass Fiber Reinforced Epoxy Composite', (Journal of Reinforced Plastics and Composites, January 1, 2007).

[8] American Society for Testing and Materials. ASTM D790-15. Standard - Test Methods for Flexural Properties of Unreinforced and Reinforced Plastics and Electrical Insulating Materials. 2015.

[9] American Society for Testing and Materials. ASTM D6110-10. Standard Test Method for Determining the Charpy Impact Resistance of Notched Specimens of Plastics.

[10] American Society for Testing and Materials. ASTM D3039-14. Standard Test Method for Tensile Properties of Polymer Matrix Composite Materials. 2014. 
[11] American Society for Testing and Materials. ASTM D695-15. Standard Test Method for Compressive Properties of Rigid Plastics. 2015.

[12] ISO 179-1:2010. Plastics - Determination of Charpy impact properties Part 1: Determination of Charpy impact properties.

[13] ISO 179-1:2010. Plastics - Determination of Charpy impact properties Part 2: Instrumented impact test.

[14]Ferreira, B. T., 'Compósitos Híbridos Reforçados com Fibras de Sisal/Vidro e Micropartículas de Sílica’. 2017. Dissertação do Programa de Pós-Graduação em Engenharia Mecânica. UFSJ.

[15] Fu, S. Y., Feng, X. Q., Lauke, B., and Mai, Y. W., 'Effects of Particle Size, Particle/Matrix Interface Adhesion and Particle Loading on Mechanical Properties of Particulate Polymer Composites', (Composite Part B, Vol. 39, No. 6, 2008, pp. 933-961).

[16]Drumond, F. B. et al. 'Metodologia de otimização de processos. Departamento de Estatística da UFMG', (Departamento de Tecnologia Mineral do CDTN/CNEM, Belo Horizonte, Minas Gerais, 1993). 